\title{
Development of Photovoltaic Agriculture in China Based on SWOT Analysis
}

\author{
Jieqiong $\mathrm{WANG}^{\mathrm{a}, 1}$, Chenchi $\mathrm{ZHANG}^{\mathrm{b}}$ and Lingxian $\mathrm{ZHANG}^{\mathrm{c}}$ \\ ${ }^{a}$ Beijing Research Center for Information Technology in Agriculture, Beijing, China \\ ${ }^{\mathrm{b}}$ National Agricultural Exhibition Center, Beijing, China \\ c China Agricultural University, Beijing, China
}

\begin{abstract}
As the coupling of photovoltaic (PV) and agriculture, PV agriculture can effectively promote the development of the PV industry and modern agriculture. PV agriculture has attracted numerous countries, prompting the emergence of a growing number of PV farms. As the largest polysilicon producer with large agricultural production area and abundant solar energy resources, China is selected as a case study. This paper identifies indicate that the weakness-threat (WT) strategy should be adopted to promote the development of PV agriculture in China by establishing a unified support policy, encouraging the participation of market capital, and promoting the development of related technology. Similarly, the Chinese scenario might provide a useful reference for other developing countries.
\end{abstract}

Keywords. Photovoltaic agriculture, modern agriculture, solar energy

\section{Introduction}

As one of the most promising energy sources, PV power generation can effectively solve environmental pollution and energy shortage caused by coal-based traditional energy. PV power generation has enormous potential for the electricity sector [1]. China, which receives $4 \mathrm{kWh} / \mathrm{m}^{2}$ annual solar radiation, has abundant solar energy resources. The total potential solar radiant energy is equal to $1.7 \times 10^{12}$ tons of standard coal per year [2]. In recent years, the PV industry of China has developed rapidly and become the fastest renewable energy industry after wind power generation globally [3]. However, China's solar cell consumption is mainly for exporting, the lag in domestic PV market development diametrically results in overcapacity, hindering the development of the PV industry in China [4].

At present, large PV power stations dominated the PV application market in China [5]. These ground power stations were mainly built in Xinjiang, Qinghai, Gansu, Inner Mongolia, and other western regions with abundant solar energy resources and large wasteland areas. Owing to the limited electricity demand in the western regions, the electricity generated in the western regions should be transported to the industrial developed eastern regions. However, the transportation in high cost due to the long-distance, the fluctuation of solar radiation, wind sand and so on. PV power curtailment is a serious occurrence, and the pace of construction is slowing down in

${ }^{1}$ Corresponding Author, Jieqiong WANG, Beijing Research Center for Information Technology in Agriculture, Beijing, China; Email: 1606540358@qq.com. 
western regions [6]. Despite sufficient electricity demand in eastern regions, the traditional ground PV power station remains difficult to spread in a large scale because of limited land resources [7]. The domestic market structure urgently has to be adjusted to meet the development demand of the PV industry in China.

The combination of the PV industry and agriculture can effectively eliminate the contradiction between solar energy, land resources, and electricity demand. It can achieve compatibility and complementarity of land, solar energy, and electricity demand and simultaneously match the demand for intensive, modern, and efficient facilities in agricultural production [8-11]. Owing to the reliable and stable profit from PV power generation, the combination of PV and agriculture can continuously increase the income of farmers, reducing the tendency of returning to poverty and conforming to precise poverty alleviation [12]. Currently, PV poverty alleviation has become one of the important forms of "hematopoietic" poverty alleviation in China [13]. Therefore, PV agriculture in China, which have broad prospects for development.

\section{Coupling Mechanism of PV Agriculture}

According to relevant literatures, there are two kinds of combinations of PV and agriculture. One kind is that directly combines the PV system with agricultural production by sharing the solar energy and land resources, which has been defined as "agrivoltaics" [14-16]. The other one is that combines PV power generation with agricultural or rural living facilities, providing power for agricultural activities. In this paper, PV agriculture refers to all kinds of combinations of PV and agriculture that underlying the principle of sharing solar energy and space without affecting the nature and agricultural production of the original land. As the coupling of PV and agriculture realized by the integration of multiple technologies, the application of equipment and the integration of industries (figure 1).

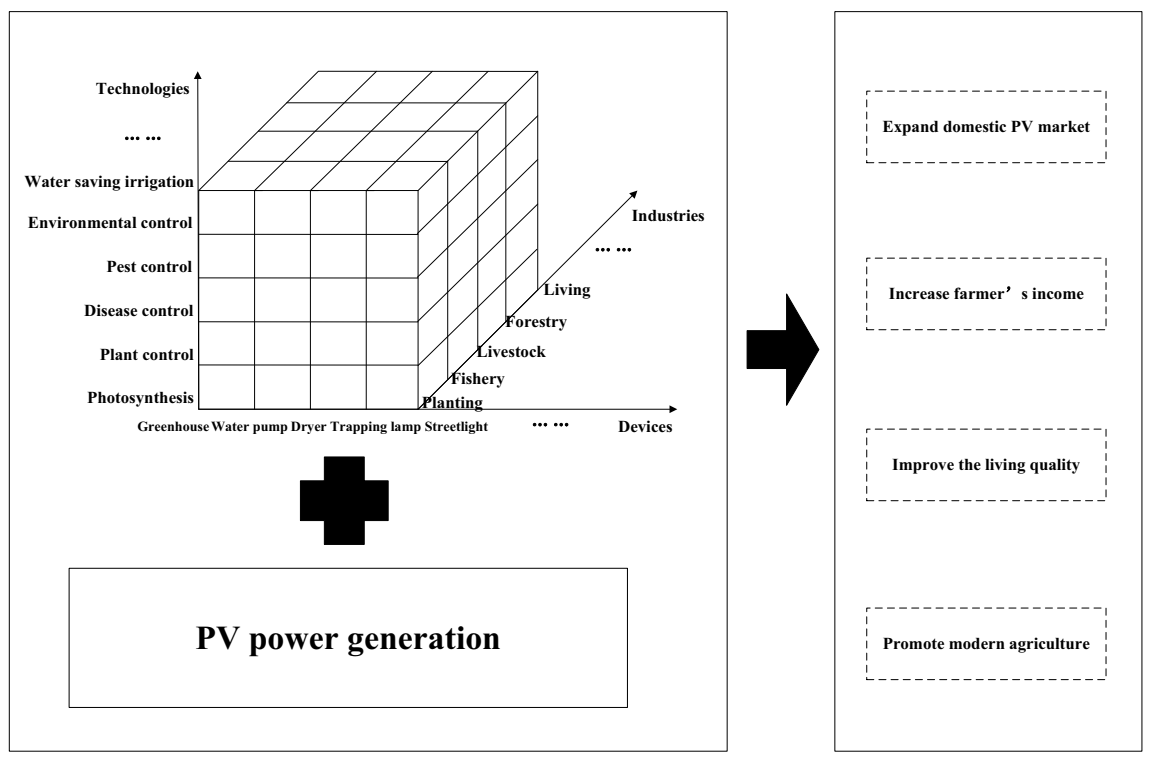

Figure 1. The coupling mechanism of PV agriculture. 
From the industrial perspective, the industrial coupling of PV agriculture including the multiple combinations of PV with agricultural industry (planting, livestock, fishery, and forestry), tertiary industry (tourism, leisure, catering) that based on the landscape and cultural functions of agriculture. Besides, PV system can also combine with rural life by utilizing vacant land or combine with related rural living facilities. From the technical perspective, the technical coupling of PV agriculture including the multiple combinations of PV technology with photosynthesis, plant breeding, disease and pest control, environmental control, agricultural information and other agricultural technologies. From the equipment perspective, the equipment coupling of PV agriculture including the specific agricultural equipment and rural living facilities, which powered by PV systems. Such as PV artificial lighting, PV cooling, PV irrigation, PV storage, PV dryer, and so on.

PV agriculture can effectively increase the utilization efficiencies of land and solar energy resources, simultaneously. For agriculture, the multiple industrial coupling exerts the landscape and cultural functions of agriculture, the multiple technical coupling increases both agricultural productivity and quality of agricultural products, the equipment coupling enhances the level of agricultural mechanization, the replacement of solar energy to traditional fuel energy used by agricultural activities promotes the development of ecological agriculture. For PV industry, PV agriculture expands the domestic PV application market, reduce the dependence on foreign markets, and reduce the government financial input for supporting PV industry by combining PV support policies with agricultural and rural support policies. For rural residents, PV agriculture brings economic benefits by increasing agricultural income and adding electricity, the multiple industrial coupling leads to multi-sustainable additional income, the multiple technical coupling and the equipment coupling reduce the labor intensity, the equipment coupling also can directly improve the rural living quality by providing power for rural living facilities.

\section{SWOT Analysis of the Development for PV Agriculture in China}

\subsection{Strengths}

Increase in income of farmers. PV energy seem less costly than other renewable energies and more profitable in rural areas, particularly in the power supplying to farms [17]. The additional income gained by installing the PV agriculture system would exceed the sale price of the agricultural land itself in most cases [16]. Compared with conventional agricultural practice, PV agriculture may be higher in productivity, with increases in overall land productivity as high as $60 \%-70 \%$, and generate an increase of over $30 \%$ in economic value [10]. Most DPV power generation projects have a return rate of $8 \%$ or higher [5]. For PV greenhouses, the annual return on investment (AROI) varies from about $9 \%$ to $20 \%$, depending on the crop variety. The discounted payback period (DPP) is 4-8 years, which is shorter than that for conventional greenhouses. Therefore, PV greenhouses can more easily obtain economic benefits, compared with conventional greenhouses.

Zero pollution emission. The growing demand for electricity has led to a continuous increase in generating capacity in China. In 2017, the generating capacity reached 6,500 billion $\mathrm{KWh}$, reflecting an increase of $5.9 \%$ over that in the previous year. Although the PV power generation comprised only $1.5 \%$ of the total power 
generation, PV power generation recorded the highest growth rate, 57.1\%. PV power generation exhibits considerable potential to replace coal-fired power generation in the future. Apart from effectively replacing the consumption of coal resources and reducing the surface mining; PV power produces no pollution emissions. In addition, PV power requires no motor, generator, or other rotating equipment, eliminating noise pollution during power generation. The annual generating capacity of $\mathrm{PV}$ in China was about 96.7 billion $\mathrm{kWh}$ in 2017 , which is equivalent to $1.1884 \times 1010 \mathrm{~kg}$ standard coal. Reducing $\mathrm{SO}_{2}$ emissions reached $1.9252 \times 108 \mathrm{~kg}$, and $\mathrm{NO}_{\mathrm{X}}$ emissions reached $2.2342 \times 107 \mathrm{~kg}$.

Improvement of rural electrification. The primary goal of solar power generation is to supply power to remote areas [18]. About $70 \%$ of exploited and used renewable energy in China in 2005 was dedicated to domestic power use in remote and rural areas with low population densities and high costs of grid connection. In these areas, renewable energy sources, such as wind and solar energy, have been identified as the least costly alternatives. Before 2008 , as an economical and sustainable alternative for meeting the energy needs of remote rural households, the off-grid PV was the largest market for PV applications in rural areas in China [19]. Solving the difficulty in rural electrification is always one of the main targets of building PV power stations. The application of PV agriculture can change the single structure of rural electrification that mainly consists of thermal power generation, as well as alleviate the serious gap in local power generation. PV agriculture can diversify power supply from local power grids and the sustainable development of local power. PV agriculture provides development opportunities for rural electrification.

Expansion of domestic photovoltaics market. PV agriculture is currently regarded as a major component of the energy sector [20]. It can effectively expand domestic PV consumption and improve the stability of PV industry in China. According to "Opinions on the implementation of photovoltaic poverty alleviation," the scale of the corresponding project in the form of a village-level or household-level PV poverty alleviation power station should be $5 \mathrm{~kW}$; the scale of the corresponding projects in the form of a centralized PV poverty alleviation power station should be 25 $\mathrm{kW}$. To reach the target that ensures an increase of more than $3000 \mathrm{RMB}$ in annual income for 2 million poor people without the ability to work in 471 counties before 2020, the scale of the PV poverty alleviation power station is at least $10 \mathrm{GW}$. Coupled with other PV agriculture modes, PV agriculture is expected to occupy the dominant position of the domestic PV market in China.

\subsection{Weaknesses}

High cost of investment. Currently, the profit gained from short-term PV agriculture is relatively low. A long period is needed to recover the cost because of the high cost of PV facilities and large one-time investment. Similar to that of the PV vegetable greenhouse, the average construction cost (including the cost of facilities for power generation, temperature control, lighting, and irrigation) of $\mathrm{PV}$ agriculture is in the $350-450 \mathrm{RMB} / \mathrm{m}^{2}$ range, and some even reach $750 \mathrm{RMB} / \mathrm{m}^{2}$. The high cost prevents general farmers from this undertaking [21]. The farmer is the main participant and operator of PV agriculture. The high cost can hinder the development of PV agriculture by discouraging farmer participation. For PV poverty alleviation projects, the one-time input of each household is about 30,000 RMB. 
Immature related technology. As an emerging industry, PV agriculture is entangled in technical delays. Although Chinese researchers have been engaged in related scientific research since the $1950 \mathrm{~s}$, the industrialization of PV agriculture in China remains delayed because of the related immature technologies and high costs. The generated electricity from PV agriculture is not yet been linked to the grid at cost price in China. The current PV power generation technology remains dominated by polysilicon, which exhibits heaviness, non-deformability, and poor transmittance. The application of polysilicon cells influences agricultural production under the PV greenhouse and PV forestry modes with higher costs, compared with the film battery.

Lack of industrial standard. PV agriculture quite varies from traditional agricultural production and lifestyle. However, technical standards to guide the construction and management of PV agriculture are lacking. This inadequacy prevents the development of PV agriculture and causes land transfer risks [11]. Some enterprises only use PV agriculture as an excuse to transfer the land with symbolic planting. Moreover, establishing a unified industrial standard requires complexity because PV agriculture extends to various departments of the NEA, Ministry of Agriculture (MOA), National Development and Reform Commission (NDRC), as well as local government sectors related to electricity, agriculture, and land resources.

Barriers to grid connection. The development of PV energy has faced challenges because of grid-accepting ability and system restraint. Although the State Grid Corporation of China has provided free connection services for on-grid PV projects, the grid connection procedure is complex. The unstable power output of solar energy causes voltage fluctuation and power-grid flicker. Conventional power facilities fail to fully satisfy the needs of on-grid PV; thus, grid companies have to reconstruct transmission lines and dispatch infrastructures. This reconstruction results in the high cost of purchasing power [7].

\subsection{Opportunities}

Abundant solar energy resources. China is a typical solar rich area. Two-thirds of the land area has solar irradiation of more than $2200 \mathrm{~h}$ annually (table 1). The average annual solar energy per unit area is more than $5000 \mathrm{MJ} / \mathrm{m}^{2}$, and total annual solar

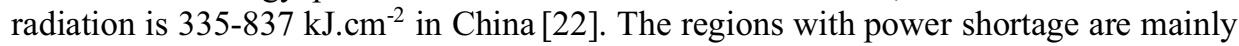
distributed in areas with high light intensity. The construction of PV agricultural projects in such areas can alleviate the power shortage caused by the failure of the traditional power grid to a certain extent.

Largest photovoltaic producer. China is currently the largest polysilicon producer worldwide, with its capacity reaching 190 thousand tons and $42.22 \%$ of the total capacity globally. The production of silicon and battery modules are concentrated in China, with production capacities of 47 and $56.7 \mathrm{GW}$, comprising $65.46 \%$ and $70.88 \%$ of the total capacity worldwide, respectively. With the continuous upgrade of Chinese enterprise technology, decrease in production cost, and growth of the terminal market, the capacity utilization rates of silicon, silicon crystal cells, and silicon crystal components have reached $88.95 \%, 87.23 \%$, and $75.84 \%$, respectively.

Large agricultural production area. China is a large and important country of agricultural producers and consumers. The cultivated land, forest, grassland, freshwater, and tideland have areas of 99, 115, 319, 17, and 2 million $\mathrm{hm}^{2}$, respectively [23]. China is also the largest agricultural equipment country covering $70 \%-80 \%$ of the total equipment area globally. Greenhouse planting has become the most beneficial 
way of agricultural planting in the past 20 years, the area reached 1.013 million hectares. Greenhouses are mainly concentrated in the provinces of Shandong, Jiangsu, and Jiangxi, which have rich solar resources for planting and PV facilities. At present, the national vegetable greenhouse area is conservatively estimated at about 50 million $\mathrm{Mu}$, providing a practical basis for PV agriculture and modern agricultural production.

Table 1. The solar resources in China [2].

\begin{tabular}{|c|c|c|c|c|}
\hline Type & $\begin{array}{l}\text { Annual } \\
\text { sunshine } \\
\text { hours (h/a) }\end{array}$ & $\begin{array}{l}\text { Total annual } \\
\text { solar radiation } \\
\left(\mathrm{MJ} / \mathrm{m}^{2} \text { a) }\right.\end{array}$ & $\begin{array}{l}\text { Equivalent to } \\
\text { standard } \\
\text { coal-fired (kg) } \\
\end{array}$ & Provinces \\
\hline I Richest & $3200-3300$ & $6680-8400$ & $225-285$ & $\begin{array}{l}\text { Northern Ningxia, Northern Gansu, } \\
\text { Southeastern Xinjiang, Western Qinghai, and } \\
\text { Western Tibet }\end{array}$ \\
\hline II Rich & $3000-3200$ & $5852-6680$ & $200-225$ & $\begin{array}{l}\text { Northwestern Hebei, Northern Shanxi, } \\
\text { Southern Inner Mongolia, Southern Ningxia, } \\
\text { Central Gansu, Eastern Qinghai, Southeastern } \\
\text { Tibet and Southern Xinjiang }\end{array}$ \\
\hline III Medium & $2200-3000$ & $5016-5852$ & $170-200$ & $\begin{array}{l}\text { Southeastern Shandong, Southeastern Henan, } \\
\text { Northwestern Hebei, Southern Shanxi, } \\
\text { Northern Xinjiang, Jilin, Liaoning, Yunnan, } \\
\text { Northern Jiangsu, Northern Anhui, Tianjin, } \\
\text { Beijing, and Southwestern Taiwan }\end{array}$ \\
\hline IV Poor & $1400-2000$ & $4190-5016$ & $140-170$ & $\begin{array}{l}\text { Hunan, Hubei, Guangxi, Jiangxi, Zhejiang, } \\
\text { Northern Fujian, Northern Guangdong, } \\
\text { Southern Shananxi, Southern Anhui, } \\
\text { Heilongjiang and Northeastern Taiwan }\end{array}$ \\
\hline V Poorest & $1000-1400$ & $3344-4190$ & $115-140$ & Sichuan, Guizhou and Chongqing \\
\hline
\end{tabular}

National support for photovoltaic agriculture. In recent years, the Chinese government has continuously strengthened its support for the PV industry to transform the mode of economic growth and fulfill its commitments to reduce emissions. Since implementation of the Golden Sun project and the PV tariff policy, the domestic PV market has increased rapidly. The policy environment for PV industrial development has gradually improved. In 2015, the government proposed to accelerate PV poverty alleviation, support the connection of PV power generation facilities to the power grid, and develop PV agriculture. The government also suggested building the concentration areas of PV agriculture and PV fishery in eastern coastal provinces, as well as the developed areas of modern agriculture, such as Shandong, Anhui, Jiangsu, Zhejiang, and Guangdong. The national determination of promoting PV agriculture is apparent.

Reducing the cost of PV power generation. The cost of solar PV has decreased rapidly in recent years. This trend is expected to continue with the continuous advances in technology, increase in conversion efficiency, and reduction in the cost and selling price of PV modules. In 2017, the price of domestic polysilicon chips, battery chips, and components decreased by $26.1 \%, 25.7 \%$, and $33.3 \%$ respectively. According the data from China's National Energy Administration, the cost of PV power generation declines to about $7 \mathrm{RMB} / \mathrm{W}$, and the cost of component was reduced to about 3 $\mathrm{RMB} / \mathrm{W}$. According the data from International Renewable Energy Agency, the global weighted average levelized cost of electricity (LCOE) of solar PV is estimated to have decreased by as much as $59 \%$ by 2025 . With such tendency, increased economic efficiency can be achieved by installing PV agriculture projects in the future. 


\subsection{Threats}

Lack of targeted support policies. The preferential policies of the state for PV agriculture continues to rely on a single target of PV power generation or agriculture, and there is no targeted support policy for PV agriculture. Although the PV policies promote the development of PV agriculture to a certain extent, the policies also trigger the pursuit for maximum profit from PV generation regardless of agricultural production. PV agriculture is administered by more than one government sector related to the departments of Reform Commission, Land, Electricity, Agriculture, Water Conservancy, Fishery, and Environmental Protection. Consequently, local leading industries, financial resources, and leaders' understanding lack consistency. In addition, the establishment of unified support policies for PV agriculture entails complexity.

High management risk. At present, PV agriculture has rapidly progressed. The wide distribution and small installed power capacity of PV agriculture at the household level result in challenges to achieving unified management. In addition, the high risk of agricultural production and management, as well as the weak capacity of maintenance, can lead to high management risks. The economic benefits of PV agriculture are vulnerable to solar energy resource, policy guidance, and development strategy. PV agriculture cannot obtain stable economic benefits.

Declining Feed-in Tariffs. Some farmers adopt PV agriculture, driven by idealism, eco-attitudes, and environmental awareness. The more prominent monetary incentives (perception of the benefits) play a strong role in the adoption of PV agriculture. Feed-in-tariffs (FIT) is the most widely known government subsidy for boosting PV installed capacity worldwide. However, as the guarantee for greater and steadier cash inflow and bank loans, FITs have gradually declined. That directly reduced the revenue from power generation and the enthusiasms of farmers to adopt PV agriculture. If the decrease in rate of FIT is too high, future installation targets and cost reduction may not be achieved [19].

\section{Development Path of PV Agriculture in China}

\subsection{Development Strategies of PV Agriculture in China}

According to the SWOT strategic matrix, four developmental strategy combinations have been identified: strengths-opportunities (SO), weaknesses-opportunities (WO), strengths-threats (ST), and weaknesses-threats (WT) [24]. In the present study, the four strategies as follows: in the SO case, the application range of PV in agriculture should be expanded in the regions with abundant resources, and the economic benefit of PV agriculture should be increased. In the WO case, the government should pay increased attention toward the investment in technical research and the construction of power grid. In the ST case, the income of the farmers should be ensured by implementing subsidy and reducing the cost of power generation. In the WO case, a unified support policy, market capital introduction, and related technology development are necessary (table 2). 


\subsection{Strategic Path Selection of PV Agriculture in China}

The basic principles underlying the design of strategies is "maximizing strengths and opportunities, transforming weaknesses to strengths, and minimizing threats" [25]. As abundant opportunities as well as social, economic, and ecological benefits are brought about by PV agriculture, weaknesses urgently have to be amended, and external threat to the health and sustainable development of PV agriculture in China should be improved. Therefore, this study proposed the weakness-threat (WT) strategy, which encourages determining the best solution to the internal problems and prevent the destructive impact of external threats [26].

Introducing market capital. Although the price of the PV system has declined in recent years, the initial investment required for PV agriculture remains high. General farmers, particularly the impoverished ones, have a long cost recovery period. The high initial investment can hinder the awareness and application of PV agriculture. In addition, the continuously declining FITs has negatively affected the attitude of the farmers regarding the adoption of PV agriculture. Therefore, market capital has to be introduced to reduce the threshold of PV agricultural construction and ensure the basic income of farmers by sharing the benefit and risk of such investment.

Table 2. SWOT strategic matrix of China's PV agriculture.

\begin{tabular}{|c|c|c|}
\hline External & Strength & Weakness \\
\hline Internal & $\begin{array}{l}\text { > S1: Increase farmers' income; } \\
\text { > S2: Zero pollution emission; } \\
\text { > S3: Improve rural electrification; } \\
\text { > S4: Expand the domestic market. }\end{array}$ & $\begin{array}{l}>\mathrm{W} 1 \text { : High cost of investment; } \\
>\mathrm{W} 2 \text { : Immature related technology; } \\
>\mathrm{W} 3 \text { : Lack of industrial standard; } \\
>\mathrm{W} 4 \text { : Barriers to grid connection. }\end{array}$ \\
\hline Opportunity & SO strategy combination & WO strategy combination \\
\hline $\begin{array}{l}\text { O1: Abundant solar } \\
\text { energy resources; } \\
\text { >O2: Largest } \\
\text { photovoltaic producer; } \\
>\text { O3: Largest agriculture } \\
\text { producer; } \\
\text { >O4: National policy } \\
\text { support; } \\
>\text { O5: Decreasing cost of } \\
\text { PV system. }\end{array}$ & $\begin{array}{l}>\mathrm{SO} 1 \text { : Increase economic benefit of } \\
\mathrm{PV} \text { agriculture; } \\
\text { SO2: Expand the application of PV } \\
\text { in agriculture. }\end{array}$ & $\begin{array}{l}>\text { WO1: Increase national investment } \\
\text { in technical research; } \\
>\text { WO2: Enhance the power grid } \\
\text { construction. }\end{array}$ \\
\hline Threat & ST strategy combination & WT strategy combination \\
\hline $\begin{array}{l}\text { DT1: Lack of targeted } \\
\text { support policies; } \\
\text { > T2: High management } \\
\text { risk; } \\
\text { > T3: Declining Feed-in } \\
\text { Tariffs. }\end{array}$ & $\begin{array}{l}>\mathrm{ST} 1 \text { : Reduce power generation cost; } \\
\text { ST2: Implement subsidy to guarantee } \\
\text { the farmers' income. }\end{array}$ & $\begin{array}{l}>\text { WT1: Establish unified support } \\
\text { policy; } \\
>\text { WT2: Introduce market capital; } \\
>\text { WT3: Develop related technology. }\end{array}$ \\
\hline
\end{tabular}

Promoting the development of related technology. Immature technology has been identified as the main reason for the limited use of PV in agriculture and the reduction of agricultural production [27]. The government should further increase investment in R\&D funding, encourage active participation of research institutions and related enterprises in relevant technology research, and promote the integration of production, marketing, and research. Management should be strengthened by reducing the manufacturing cost of the PV power generation system and improve the conversion 
efficiency and service life of PV cells, combined with the agricultural production demand as well as the assistance of big data, the Internet of Things, and other new technologies. In addition, the upgrade of the PV agricultural technology system should be promoted by integrating PV technology with agronomic and agricultural machinery technologies. These advances in related technology can reduce the construction and operating costs of PV agriculture, as well as indirectly enhance the economic benefits.

Establishing a unified support policy. The current development of PV agriculture mainly depends on PV industrial policies or PV poverty alleviation policies and without PV agriculture in the overall consideration. A certain unified policy should be established to support and guide the development of PV agriculture from the perspectives of construction, operation, sales and profit, with consideration of the characteristics of the PV industry and agricultural development. In construction, the policy should focus on support for PV agricultural land and construction funds to increase farmer participation. In operation, subsidies should be provided in accordance with agricultural production to alleviate the problem of "heavy PV and light agriculture". In profit distribution, improve the profit distribution mechanism, set the minimal purchase price to ensure the fundamental interests of farmers.

\section{Conclusion}

China, the largest PV manufacturer worldwide, is a large agricultural country with abundant solar energy resources. PV agriculture has great potential in China. The three-dimensional coupling mechanism of PV agriculture was proposed to support the basic theoretical framework of PV agriculture engineering. PV and industry coupling is the specific application of PV agriculture; the PV and technical coupling is the key to the realization of the PV and industrial coupling; PV and equipment coupling is the important carrier to realize industrial and technical coupling of PV agriculture in engineering. To promote the health and sustainable development of PV agriculture in China, the government should encourage the participation of market capital, promote the development of related technology, as well as establish the unified support policy system. In addition, the government should explore the potential of PV agriculture as an important tool to regulate the power structure of China and to improve agricultural production and life.

\section{References}

[1] Comello S, Reichelstein S and Sahoo A 2018 Renew. Sust. Energ. Rev. 92 744-56.

[2] Zhao Z, Zhang S, Hubbard B and Yao X 2013 Renew. Sust. Energ. Rev. 21 229-36.

[3] Zhang L, Wang J, Wen H, Fu Z and Li X 2016 Renew. Sust. Energ. Rev. 65 373-86.

[4] Zhao X, Zeng Y and Zhao D 2015 Energy 88 572-83.

[5] Luo G, Long C, Wei X and Tang W 2016 Renew. Sust. Energ. Rev. 63 93-101.

[6] Shen W 2016 Environ. Dev. 21 87-97.

[7] Zhang S 2016 Energy 98 92-100.

[8] Valle B, Simonneau T, Sourd F, Pechier P, Hamard P, Frisson T, Ryckewaert M and Christophe A 2017 Appl. Energy 206 1495-1507.

[9] Liu W, Liu L, Guan C, Zhang F, Li M, Lv H, Yao P and Ingenhoff J 2018 Sol. Energy 162 84-94.

[10] Krishnan R and Pearce J M 2018 Land Use Pol. 72 503-9.

[11] Liu W and Liu L 2016 Optics \& Optoelectronic Technol. 14 1-4.

[12] Wu Y, Ke Y, Zhang T, Liu F and Wang J 2018 Energy 159 599-610. 
[13] Li Y, Zhang Q, Wang G, Mclellan B, Liu X and Wang L 2018 Renew. Sust. Energ. Rev. 94 214-23.

[14] Malu P R, Sharma U S and Pearce J M 2017 Sustain. Energy Technol. Assess. 23 104-10.

[15] Amaducci S, Yin X and Colauzzi M 2018 Appl. Energy 220 545-61.

[16] Majumdar D and Pasqualetti M J 2018 Landsc. Urban Plan. 170 150-68.

[17] Maammeur H, Hamidat A, Loukarfi L, Missoum M, Abdeladim K and Nacer T 2017 Renew. Sust. Energ. Rev. 78 1208-20.

[18] Liu D and Shiroyama H 2013 Renew. Sust. Energ. Rev. 25 782-792.

[19] Huo M and Zhang D 2012 Energy Policy 51 38-45.

[20] Thao N and Uchida K 2017 Control Eng. Practice 59 77-99.

[21] Peng M 2012 China Southern Agricultural Machinery 2 4-6.

[22] Zheng M, Xue S, Ma M and Zhu X 2013 Renew. Sust. Energ. Rev. 20 169-85.

[23] Jiang G, Xu P, Liu H, Wu Z, Cao L and Zhang Q 2016 Journal of Anhui Agriculture Science 44 60-2.

[24] Zhao X, Kang J and Lan B 2013 Renew. Sust. Energ. Rev. 21 603-13.

[25] Jiang R, Mao C, Hou L, Wu C and Tan J 2018 J. Clean Prod. 173 225-34.

[26] Malgorzata J K 2016 IFAC Papers Online 49 674-9.

[27] Wu N, Zhang Y, She W, Zhang C and Yuan Q 2018 Vegetables 4 1-7. 